\title{
Hypoxia-inducible factor: role in cell survival in superoxide dismutase overexpressing mice after neonatal hypoxia-ischemia
}

\author{
Ga Won Jeon, MD, PhD', R. Ann Sheldon, MA², Donna M. Ferriero, MD, MS ${ }^{2}$ \\ ${ }^{1}$ Department of Pediatrics, Inje University Busan Paik Hospital, Inje University College of Medicine, Busan, Korea, ${ }^{2}$ Departments of Pediatrics and Neurology and \\ Newborn Brain Research Institute, University of California San Francisco, San Francisco, CA, USA
}

Background: Sixty percent of infants with severe neonatal hypoxic-ischemic encephalopathy die, while most survivors have permanent disabilities. Treatment for neonatal hypoxic-ischemic encephalopathy is limited to therapeutic hypothermia, but it does not offer complete protection. Here, we investigated whether hypoxia-inducible factor (HIF) promotes cell survival and suggested neuroprotective strategies. Purpose: HIF-1 $1 \alpha$ deficient mice have increased brain injury after neonatal hypoxia-ischemia (HI), and the role of HIF-2 2 in HI is not well characterized. Copper-zinc superoxide dismutase (SOD)1 overexpression is not beneficial in neonatal $\mathrm{HI}$. The expression of HIF-1 $\alpha$ and HIF-2 $\alpha$ was measured in SOD1 overexpressing mice and compared to wild-type littermates to see if alteration in expression explains this lack of benefit. Methods: On postnatal day 9, C57BI/6 mice were subjected to $\mathrm{HI}$, and protein expression was measured by western blotting in the ipsilateral cortex of wild-type and SOD1 overexpressing mice to quantify HIF-1 $\alpha$ and HIF-2 $\alpha$. Spectrin expression was also measured to characterize the mechanism of cell death.

Results: HIF-1 $\alpha$ protein expression did not significantly change after HI injury in the SOD1 overexpressing or wild-type mouse cortex. However, HIF-2 $\alpha$ protein expression increased 30 minutes after $\mathrm{HI}$ injury in the wild-type and SOD1 overexpressing mouse cortex and decreased to baseline value at 24 hours after $\mathrm{HI}$ injury. Spectrin 145/150 expression did not significantly change after HI injury in the SOD1 overexpressing or wild-type mouse cortex. However, spectrin 120 expression increased in both wild-type and SOD1 overexpressing mouse at 4 hours after $\mathrm{HI}$, which decreased by 24 hours, indicating a greater role of apoptotic cell death.

Conclusion: HIF-1 $\alpha$ and HIF-2 $\alpha$ may promote cell survival in neonatal $\mathrm{HI}$ in a cell-specific and regional fashion. Our findings suggest that early HIF-2 $\alpha$ upregulation precedes apoptotic cell death and limits necrotic cell death. However, the influence of SOD was not clarified; it remains an intriguing factor in neonatal $\mathrm{HI}$.

Key words: Brain injury, Cell death, Hypoxia-inducible factor, Hypoxic-ischemic encephalopathy, Superoxide dismutase

\section{Key message}

Question: Can we treat neonatal hypoxic-ischemic encephalopathy?

Finding \& Meaning: Both HIF-1 $\alpha$ and HIF-2 $\alpha$ may promote cell survival in animal model of neonatal hypoxia-ischemia. Developmental age, degree and type of injury are all factors in the expression and action of HIF- $1 \alpha$ and HIF-2 $\alpha$. Early HIF-2 $\alpha$ upregulation precedes apoptotic cell death and may limit necrotic cell death in animal model of neonatal hypoxia-ischemia.
Corresponding author: Ga Won Jeon, MD, PhD Department of Pediatrics, Inje University Busan Paik Hospital, Inje University College of Medicine, 75 Bokji-ro, Busanjin-gu, Busan 47392, Korea Tel: +82-51-890-6497

Fax: +82-51-895-7785

E-mail: iamgawon@hanmail.net https://orcid.org/0000-0002-8206-9727

Received: 19 July, 2019

Revised: 19 September, 2019

Accepted: 15 October, 2019
Copyright (@ 2019 by The Korean Pediatric Society

This is an open-access article distributed under the terms of the Creative Commons Attribution NonCommercial License (http://creativecommons.org/ licenses/by-nc/4.0/ which permits unrestricted noncommercial use, distribution, and reproduction in any medium, provided the original work is properly cited. 


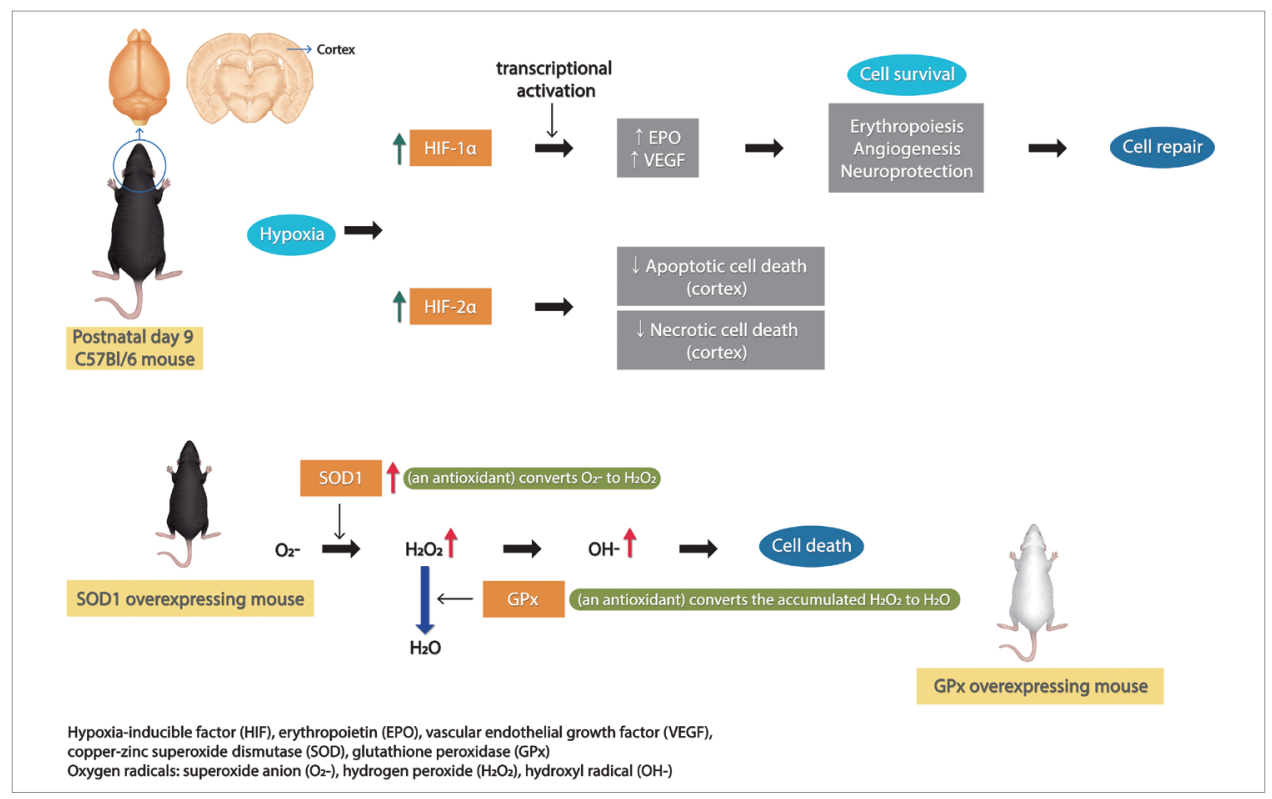

Graphical abstract. Mechanisms of cell survival mediated by HIF

\section{Introduction}

Neonatal hypoxic-ischemic encephalopathy causes death in twenty percent of affected infants, and 25\% of survivors have permanent neurologic deficits such as developmental delay, cerebral palsy, cognitive dysfunction, hearing loss, and visual loss. ${ }^{1)}$ Ten percent of moderate encephalopathy infants die and 30\% of the survivors are handicapped; $60 \%$ of severe encephalopathy infants die and most of the survivors have permanent disabilities. ${ }^{2)}$ Treatment of neonatal hypoxic-ischemic encephalopathy is limited to therapeutic hypothermia for those infants that qualify but does not offer complete protection. Several neuroprotective strategies have been suggested such as antioxidants or erythropoietin (EP0). ${ }^{3)}$

We have previously reported that hypoxia-inducible factor (HIF)- $1 \alpha$ deficient mice have increased brain injury after neonatal hypoxia-ischemia (HI). ${ }^{4)} \mathrm{HIF}-1 \alpha$ is a nuclear protein induced by hypoxia, which acts as a transcription factor crucial for activation of many protective hypoxia-inducible genes such as erythropoietin, glucose transporters, inducible nitric oxide synthase (NOS), and vascular endothelial growth factor (VEGF) ${ }^{5,6)}$ As a result, HIF-1 $\alpha$ promotes cell survival, and initiates neuroprotection, angiogenesis and subsequently, cell repair in neonatalHI. ${ }^{4,7)}$

We also have found that copper-zinc superoxide dismutase (SOD) 1 overexpression is not beneficial to the neonatal mouse brain with $\mathrm{HI}$ injury, ${ }^{8)}$ unlike the adult brain with similar injury, in which SOD1 overexpression was shown to be neuroprotective after cerebral ischemia." SOD1 is an endogenous antioxidant, which converts superoxide anion $\left(\mathrm{O}_{2}^{-}\right)$to hydrogen peroxide $\left(\mathrm{H}_{2} \mathrm{O}_{2}\right)$ in neurons of the $\mathrm{HI}$ brain. Glutathione peroxidase (GPx) converts the accumulated
$\mathrm{H}_{2} \mathrm{O}_{2}$ to $\mathrm{H}_{2} \mathrm{O}$ and $\mathrm{O}_{2}$. However, SOD1 overexpression causes high $\mathrm{H}_{2} \mathrm{O}_{2}$ accumulation after $\mathrm{HI}$ in the neonatal brain, but not the adult. ${ }^{10)}$ The accumulation of $\mathrm{H}_{2} \mathrm{O}_{2}$ and hydroxyl radical $(\mathrm{OH})$ causes nitric oxide radical production by NOS, lipid peroxidation, protein oxidation, DNA damage, and finally neuronal death via necrosis or apoptosis. ${ }^{11)}$ These data illustrate that neuroprotective mechanisms of the developing neonatal brain are different from mature brain. We explored whether the expression of HIF- $1 \alpha$ and HIF- $2 \alpha$ were altered in SOD1 overexpressing mouse brain compared to wild-type littermates to explain this increased injury in neonatal brain.

\section{Methods}

This animal study was approved by the University of California San Francisco (UCSF) institutional animal care and use committee in accordance with National Institutes of Health (NIH) guidelines for the care and use of laboratory animals. C57Bl/6 mice and SOD1 overexpressing littermates were subjected to the Vannucci model of neonatal HI. ${ }^{12-14)}$ At postnatal day (P) 9, pups were anesthetized with isoflurane (3\% isoflurane/balance oxygen), the left common carotid artery was dissected after a midline incision of the neck and the artery was ligated with electrical coagulation. Animals were allowed to recover for 1 hour with the dam and then exposed to 50 minutes of hypoxia in a humidified chamber at $36.5^{\circ} \mathrm{C}$ with $10 \%$ oxygen/balance nitrogen. Sham-operated control animals received isoflurane anesthesia and exposure of the left common carotid artery without ligation or hypoxia. Pups were sacrificed at designated times after injury (30 minutes, 4 hours, or 24 hours) by decapitation 
after intraperitoneal injection of Euthasol. Brains cortices were dissected on a cold pad, placed in labeled prechilled microfuge tubes, flash frozen in methylbutane on dry ice, then stored at $-80^{\circ} \mathrm{C}$ until use. Animals used in each group were 10, 11, 15, 13, 7, 13, 10, and 13, in wild-type sham, SOD1 overexpressor sham, wild-type 30 minutes, SOD1 overexpressor 30 minutes, wild-type 4 hours, SOD1 overexpressor 4 hours, wild-type 24 hours, and SOD1 overexpressor 24 hours after HI, respectively.

Western blot analysis was performed on ipsilateral cortex from wild-type and SOD1 overexpressing mice to quantify HIF-1 $\alpha$, HIF$2 \alpha$, spectrin 120 as a neuronal apoptosis marker, and spectrin 145/ 150 as a neuronal necrosis marker at 30 minutes, 4 hours, and 24 hours after HI injury.

Frozen cortices were homogenized and cytoplasmic and nuclear proteins were extracted with NE-PER (nuclear and cytoplasmic extraction reagents, Pierce, Rockford, IL, USA). Protein samples were prepared with $4 \mathrm{X}$ loading buffer and sample reducing agent (10X DTT) and 40- $\mu$ g cytoplasmic protein or 20- $\mu$ g nuclear protein underwent sodium dodecyl sulfate-polyacrylamide gel electrophoresis at $150 \mathrm{~V}$ for 90 minutes. Proteins were transferred to polyvinyl difluoride membranes (Bio-Rad, Hercules, CA, USA) at $35 \mathrm{~V}$ overnight at $4^{\circ} \mathrm{C}$ as described by Chang et al. ${ }^{15)}$ The membranes were blocked in 5\% nonfat dry milk in Tris-buffered saline with Tween for at least 1 hour at room temperature with gentle shaking, then incubated with rabbit HIF-1 $\alpha$ polyclonal antibody (1:1500; Novus Biologicals, Littleton, CO, USA), rabbit HIF-2 $\alpha$ polyclonal antibody (1:500; Novus Biologicals), and rabbit histone monoclonal antibody (1: 8000; Cell Signaling Technology, Boston, MA, USA) or mouse spectrin monoclonal antibody (1:2000; Millipore, Temecula, CA,
USA) and mouse beta-actin monoclonal antibody (1:2000; Santa Cruz Biotechnology, Santa Cruz, CA, USA) overnight at $4{ }^{\circ} \mathrm{C}$. Horseradish peroxidase-conjugated goat anti-rabbit antibodies (Santa Cruz Biotechnology) were used (1:2000 for HIF-1 $\alpha$ and HIF$2 \alpha, 1: 4,000$ for histone) as secondary antibodies. Bound antibodies were developed by enhanced chemiluminescence (ECL, Amersham Life Science, Arlington Heights, IL, USA) and exposed to film. Image J software (NIH, Bethesda, MD, USA) was used to measure the optical densities (OD) and areas of protein signal on after scanning.

Data were analyzed by nonparametric tests: the Mann-Whitney $U$ test for 2 groups, and the analysis of variance with Kruskal-Wallis test for 3 or more groups. All data were analyzed using Prism 7 (GraphPad Software, La Jolla, CA, USA). Data are given as mean \pm standard error, and $P$ values $<0.05$ were considered significant.

\section{Results}

HIF-1 $\alpha$ protein expression was not significantly altered in wildtype or SOD1 overexpressing mouse cortex after HI injury (Fig. 1A). However, HIF-2 $\alpha$ protein expression increased in both wildtype and SOD1 overexpressing mouse cortex, reaching peak levels of 7-fold for wild-type and 5-fold for SOD1 overexpressors at 30 minutes after HI injury (Fig. 1B). The level of HIF-2 $\alpha$ decreased at 4 hours and returned to baseline at 24 hours (Fig. 1B). There were no differences between SOD1 overexpressors and wild-type littermates by time point.

Spectrin 145/150 protein expression was not significantly altered in wild-type or SOD1 overexpressing mouse cortex after HI injury
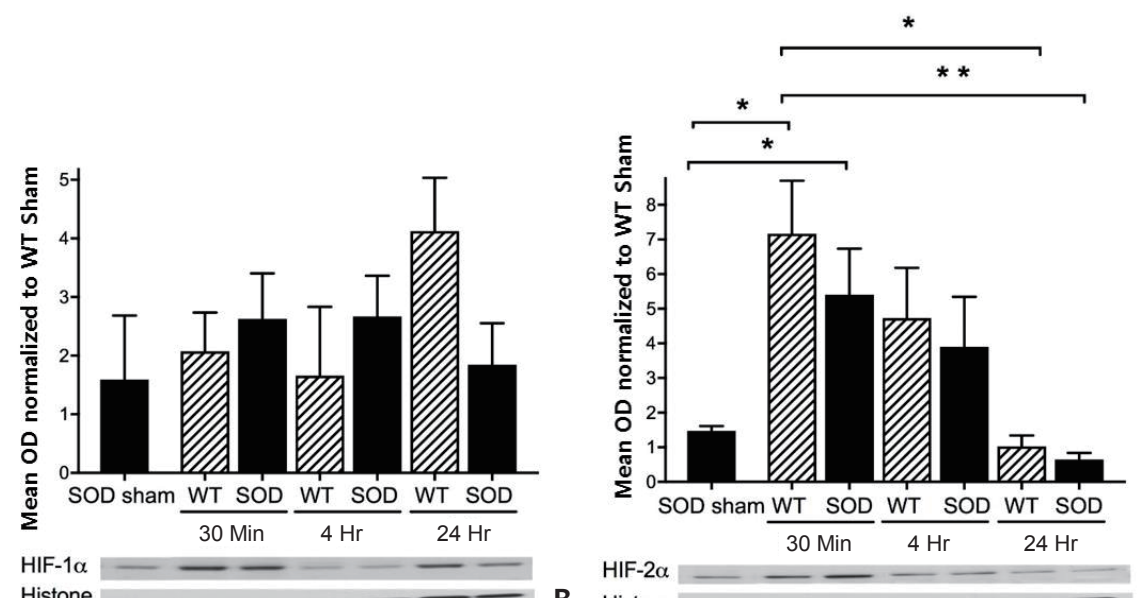

Fig. 1. Hypoxia-inducible factor (HIF)-1 $\alpha$ and HIF-2 $\alpha$ protein expression in the cortex of wild-type (WT) and copper-zinc superoxide dismutase (SOD)1 overexpressing mice. Protein expression in the cortex of WT and S0D1 overexpressing sham, 30 minutes, 4 hours, and 24 hours after hypoxia-ischemia (HI). Data are shown as optical densities (OD) normalized to WT sham. (A) HIF-1a was not significantly different after HI. (B) HIF-2 $\alpha$ increased in the cortex of WT and SOD1 overexpressing mice at 30 minutes $\left({ }^{\star} P<0.02\right.$ and $P<0.03$, respectively). HIF-2 $\alpha$ decreased to baseline value by 24 hours in the cortex of WT ( $\left.{ }^{*} P<0.01\right)$ and SOD1 overexpressing mice $\left({ }^{* \star} P<0.005\right)$. 


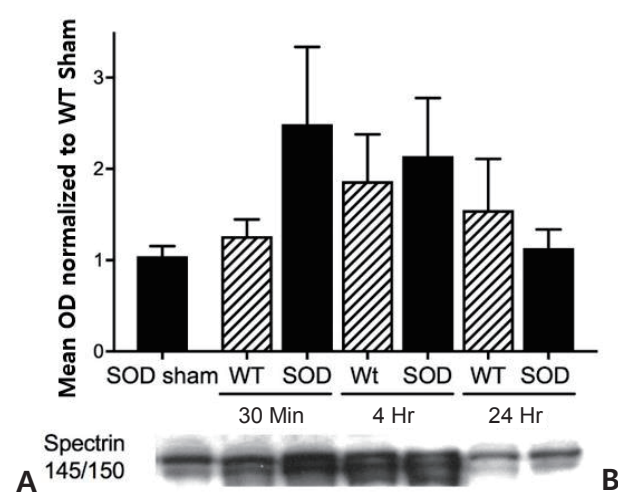

Fig. 2. Spectrin 145/150 and 120 expressions in the cortex of wild-type (WT) and copper-zinc superoxide dismutase (SOD)1 overexpressing mice. Protein expression in the cortex of WT and SOD1 overexpressing sham, 30 minutes, 4 hours, and 24 hours after hypoxia-ischemia (HI). Data are shown as optical densities (OD) normalized to WT sham. (A) Spectrin 145/150 expression was not significantly different after HI. (B) Spectrin 120 expression increased in the cortex of both WT and S0D1 overexpressing mice at 4 hours after $\mathrm{HI}\left({ }^{*} P<0.03\right.$ for both).

(Fig. 2A). However, spectrin 120 protein expression increased in both wild-type and SOD1 overexpressing mouse cortex, reaching peak levels of 3-fold for both wild-type and SOD1 overexpressors 4 hours after HI injury (Fig. 2B).

\section{Discussion}

The developing neonatal brain, with a high rate of oxygen consumption, high concentrations of unsaturated fatty acids and relative lack of antioxidants is extremely vulnerable to oxidative stress and exposure to exogenous free radicals and iron-mediated free radical injury. ${ }^{16)}$ Antioxidants protect the brain by attacking various injury cascades. These are reactive oxygen species scavengers (melatonin, SOD, catalase), inhibitors of lipid peroxidation, EPO (as a free radical reducer), inhibitors of NOS and anti-inflammatories. ${ }^{17)}$ The mechanism of neuroprotection by an iron chelator such as deferoxamine is that it activates and upregulates HIF- $1 \alpha$ expression. The upregulated HIF- $1 \alpha$ in turn activates various HIF- $1 \alpha$ mediated genes, such as $V E G F$, which initiate a complicated neuroprotective cascade. ${ }^{18,19)}$ HIF- $1 \alpha$, a subunit of HIF-1, is undetectable under normoxic conditions, which is induced by hypoxia and is promptly degraded under normoxia by the ubiquitin-proteasome pathway. ${ }^{20)}$ Like HIF-1 $\alpha$, HIF- $2 \alpha$ is induced by hypoxia. It is a less wellcharacterized factor, but has been shown to be expressed much more in astrocytes than neurons ${ }^{21)}$ and is the primary mediator of EPO expression induced by hypoxia, which is in turn protective to neurons, ${ }^{22)}$ suggesting HIF-2 $\alpha$ expression may play a bigger role in neuroprotection than HIF- $1 \alpha$. The actions of these $2 \mathrm{HIF}$ isoforms are cell-specific, regional and developmentally regulated, being complementary rather than redundant. ${ }^{23)}$

Previously, in P7 mouse cortex, we have seen increased HIF-1 $\alpha$ immediately after hypoxia alone and 24 hours after $\mathrm{HI}$. Similarly, also in P7 mouse cortex, we saw increased HIF-1 $\alpha$ immediately after hypoxia as well as at 4 hours and 24 hours after hypoxia. ${ }^{24)}$ However, HIF- $1 \alpha$ increased only immediately after $\mathrm{HI}$, not at 4 hours or 24 hours after $\mathrm{HI}^{24}{ }^{24}$ On the contrary, HIF-1 $\alpha$ decreased 4 hours after $\mathrm{HI}$ in $\mathrm{P} 9$ mouse cortex with no change in the hippocampus. ${ }^{25)}$ We also measured HIF-2 $\alpha$ in the latter study. HIF-2 $\alpha$ did not change after $\mathrm{HI}$ in cortex, but declined in hippocampus at 30 minutes, 4 hours, and 24 hours. These results corresponded with increased spectrin 145/150 at 4 hours and 24 hours in cortex, but not hippocampus, and with increased spectrin 120 at 24 hours in cortex and at 4 hours in hippocampus, ${ }^{25)}$ suggesting early and prolonged necrotic cell death with additional late stage apoptosis in the cortex, but early apoptotic cell death with a relative lack of necrotic cell death in the hippocampus. Thus, while we did not see significant changes in HIF$1 \alpha$ in the present study, we did see a strong increase in HIF-2 $\alpha$ in both wild-type and SOD1 overexpressing cortex after HI. This may be due, in part, to the above-mentioned cell-specific, regional and complementary actions of the HIF isoforms. We measured spectrin here also in order to determine if mechanism of cell death corresponded to levels of HIF- $1 \alpha$ or HIF- $2 \alpha$. Since spectrin $145 / 150$ was not elevated, but spectrin 120 was (at 4 hours), this may indicate that apoptosis has a greater role than necrosis in genesis of the $\mathrm{HI}$ injury in the critical phase several hours after the insult. The expression of HIF- $2 \alpha$ may play a bigger role in neonatal HI injury than HIF- $1 \alpha$. It is conceivable that HIF- $2 \alpha$ stimulated production of factors (such as EP0) that protected neurons from necrotic injury while astrocytes (and perhaps neurons) underwent subsequent apoptotic death. While 
we did not analyze cell type, neurons and astrocytes may have different responses to injury that are reflected in gene expression at the time points studied.

The SOD1 overexpressing cortex behaved quite similarly to the wild-type cortex with regard to expression of HIF- $1 \alpha, \mathrm{HIF}-2 \alpha$, spectrin 145/150, and spectrin 120 at the time points after HI analyzed here. Thus, alterations in expression of these factors do not explainthe increased injury we have previously seen in the SOD1 overexpressing brain compared to wild-type.

HIF- $2 \alpha$ activates transcription of mitochondrial manganese SOD (SOD2) ${ }^{26)}$ The early increase in HIF-2 $\alpha$ seen in both wild-type and SOD1 overexpressing cortex may indicate additional SOD production; a factor that warrants further study.

The activation of HIF- $1 \alpha$ and the consequence of the activation of its target genes are suggested to be necessary for protection in neonatal $\mathrm{HI}{ }^{4,11)}$ During neonatal brain injury, excitotoxicity (excessive activation of glutamate neurotransmission, oxidative stress, and inflammation) contributes to cell death either by apoptosis or necrosis. Apoptosis, or programmed cell death, seems to play a more important role than necrosis during HI injury. ${ }^{16)}$

The role of HIF-2 $\alpha$ in neonatal HI brain is relatively unexplored. HIF- $2 \alpha$ is activated by hypoxia stimulated mitogen-activated protein kinase (MAPK)/ERK signaling pathway, leading to the increased transcription of various proliferation factors. HIF-2 $\alpha$ directly binds the MAPK3 promoter and activates its function through the interaction of the transcription factor and its regulated genes. ${ }^{27)} \mathrm{In}$ cardiac myocytes in adult mice, myocyte-specific HIF-2 $\alpha$ induced the epithelial growth factor amphiregulin (AREG), activating AREG signaling, and finally protecting the myocardium from myocardial ischemia-reperfusion injury ${ }^{28)}$ In the carotid body, intermittent hypoxia leads to increased expression of HIF- $1 \alpha$ and decreased levels of HIF- $2 \alpha$ along with decreased SOD2 expression. ${ }^{29}$ In mesenchymal stem cells, HIF-2 $\alpha$ maintained significant long-term effects, and was more stable in hypoxic conditions than normoxic. ${ }^{27)}$ In the brain, HIF- $2 \alpha$ is considered to be astrocyte specific, and astrocytes are important for the clearance of $\mathrm{H}_{2} \mathrm{O}_{2}$, resulting in neuroprotection. Wildtype brain with decreased expression of HIF- $2 \alpha$ had more severe brain injury compared to GPx overexpressing brain with higher HIF$2 \alpha$. This may be a reflection of a neuroprotective effect of HIF- $2 \alpha$ associated with $\mathrm{SOD} 2$ generated $\mathrm{H}_{2} \mathrm{O}_{2}$ clearing. ${ }^{25}$ )

Increased HIF- $1 \alpha$ after HI is reported in many cases, ${ }^{4,24,30)}$ however, HIF- $1 \alpha$ is not changed or rather decreased in some cases as previously mentioned. ${ }^{25)}$ The expressions of HIF- $1 \alpha$ are different according to the time after HI, cell types (neurons vs. astrocyte), region (cortex vs. hippocampus), or developmental age (P7 vs. P9). So, these different experimental conditions partially account for these different results.

There are several limitations in this study. First, the grade of brain injury with histological analysis was not checked in the present study. Though we have shown injury severity with HI brain injury scores twice in the past, ${ }^{24)}$ the experimental conditions such as de- velopmental age (P7 vs. P9) were different from the previous study. It is not technically feasible to do histology and protein expression in the same sample. Also, spectrin is an assessment of injury which is not quite comparable to histology. Further work is needed to clarify the grade of brain injury. Second, SOD1 expression of SOD overexpressors was not checked. However, as these mice are wellcharacterized, and we have done SOD activity in the past, ${ }^{31)}$ we didn't check SOD1 expression on the transgenics in the present study. Third, we could not find difference of protein expressions after HI between wild-type and SOD1 overexpressing mouse. Some of this might be due to small number of mice underwent this experiment.

In summary, we propose that both HIF- $1 \alpha$ and HIF- $2 \alpha$ may promote cell survival in neonatal HI, but in a cell-specific and regional fashion. We also suggest that early HIF-2 $\alpha$ upregulation precedes apoptotic cell death and may limit necrotic cell death. Developmental age, degree and type of injury are all factors in the expression and action of HIF- $1 \alpha$ and HIF- $2 \alpha$. The influence of SOD was not clarified and remains an intriguing factor in neonatal $\mathrm{HI}$. Further work is needed to clarify the roles of HIF- $1 \alpha$ and HIF- $2 \alpha$ in neonatal brain injury.

\section{Conflicts of interest}

No potential conflict of interest relevant to this article was reported.

\section{Acknowledgments}

This work was supported by a grant from Research year of Inje University in 2016 (20150560) (Ga Won Jeon), and funded by NS097299 (Donna M Ferriero). We thank Ethan Lu and Xiangning Jiang, Department of Neurology, UCSF, for helping with the western blot analysis. We also thank Christine Windsor, and Olatz Arteaga Cabeza, Department of Neurology, UCSF, for helping with this animal study.

\section{References}

1. Volpe JJ. Hypoxic-ischemic injury in the term infant: pathophysiology. In: Volpe JJ, Inder TE, Darras BT, de Vries LS, du Plessis AJ, Neil JJ, et al., editors. Volpe's neurology of the newborn. 6th ed. Philadelphia (PA): Elsevier, 2018:500-9.

2. Shankaran S, Laptook AR, Ehrenkranz RA, Tyson JE, McDonald SA, Donovan EF, et al. Whole-body hypothermia for neonates with hypoxic-ischemic encephalopathy. N Engl J Med 2005;353:1574-84.

3. Gonzalez FF, Ferriero DM. Neuroprotection in the newborn infant. Clin Perinatol 2009;36:859-80, vii.

4. Sheldon RA, Osredkar D, Lee CL, Jiang X, Mu D, Ferriero DM. HIF-1 
alpha-deficient mice have increased brain injury after neonatal hypoxia-ischemia. Dev Neurosci 2009;31:452-8.

5. Bernaudin M, Tang Y, Reilly M, Petit E, Sharp FR. Brain genomic response following hypoxia and re-oxygenation in the neonatal rat. Identification of genes that might contribute to hypoxia-induced ischemic tolerance. J Biol Chem 2002;277:39728-38.

6. Ran R, Xu H, Lu A, Bernaudin M, Sharp FR. Hypoxia preconditioning in the brain. Dev Neurosci 2005;27:87-92.

7. Bergeron M, Gidday JM, Yu AY, Semenza GL, Ferriero DM, Sharp FR. Role of hypoxia-inducible factor-1 in hypoxia-induced ischemic tolerance in neonatal rat brain. Ann Neurol 2000;48:285-96.

8. Ditelberg JS, Sheldon RA, Epstein CJ, Ferriero DM. Brain injury after perinatal hypoxia-ischemia is exacerbated in copper/zinc superoxide dismutase transgenic mice. Pediatr Res 1996;39:204-8.

9. Yang G, Chan PH, Chen J, Carlson E, Chen SF, Weinstein P, et al. Human copper-zinc superoxide dismutase transgenic mice are highly resistant to reperfusion injury after focal cerebral ischemia. Stroke 1994;25:165-70.

10. Lafemina MJ, Sheldon RA, Ferriero DM. Acute hypoxia-ischemia results in hydrogen peroxide accumulation in neonatal but not adult mouse brain. Pediatr Res 2006;59:680-3.

11. Sheldon RA, Jiang X, Francisco C, Christen S, Vexler ZS, Täuber MG, et al. Manipulation of antioxidant pathways in neonatal murine brain. Pediatr Res 2004;56:656-62.

12. Rice JE 3rd, Vannucci RC, Brierley JB. The influence of immaturity on hypoxic-ischemic brain damage in the rat. Ann Neurol 1981;9:131-41.

13. Vannucci RC, Vannucci SJ. Perinatal hypoxic-ischemic brain damage: evolution of an animal model. Dev Neurosci 2005;27:81-6.

14. Wang X, Zhu C, Wang X, Hagberg H, Korhonen L, Sandberg M, et al. $\mathrm{X}$-linked inhibitor of apoptosis (XIAP) protein protects against caspase activation and tissue loss after neonatal hypoxia-ischemia. Neurobiol Dis 2004;16:179-89.

15. Chang S, Jiang X, Zhao C, Lee C, Ferriero DM. Exogenous low dose hydrogen peroxide increases hypoxia-inducible factor-1alpha protein expression and induces preconditioning protection against ischemia in primary cortical neurons. Neurosci Lett 2008;441:134-8.

16. Ferriero DM. Neonatal brain injury. N Engl J Med 2004;351:1985-95.

17. Buonocore G, Groenendaal F. Anti-oxidant strategies. Semin Fetal Neonatal Med 2007;12:287-95.

18. Li L, Yin X, Ma N, Lin F, Kong X, Chi J, et al. Desferrioxamine regulates HIF-1 alpha expression in neonatal rat brain after hypoxiaischemia. Am J Transl Res 2014;6:377-83.

19. Hamrick SE, McQuillen PS, Jiang X, Mu D, Madan A, Ferriero DM. A role for hypoxia-inducible factor-1alpha in desferoxamine neuro- protection. Neurosci Lett 2005;379:96-100.

20. Zhang L, Qu Y, Yang C, Tang J, Zhang X, Mao M, et al. Signaling pathway involved in hypoxia-inducible factor-1alpha regulation in hypoxic-ischemic cortical neurons in vitro. Neurosci Lett 2009;461:16.

21. Chavez JC, Baranova O, Lin J, Pichiule P. The transcriptional activator hypoxia inducible factor 2 (HIF-2/EPAS-1) regulates the oxygendependent expression of erythropoietin in cortical astrocytes. J Neurosci 2006;26:9471-81.

22. Yeo EJ, Cho YS, Kim MS, Park JW. Contribution of HIF-1alpha or HIF-2alpha to erythropoietin expression: in vivo evidence based on chromatin immunoprecipitation. Ann Hematol 2008;87:11-7.

23. Trollmann R, Gassmann M. The role of hypoxia-inducible transcription factors in the hypoxic neonatal brain. Brain Dev 2009;31:503-9.

24. Sheldon RA, Lee CL, Jiang X, Knox RN, Ferriero DM. Hypoxic preconditioning protection is eliminated in HIF- $1 \alpha$ knockout mice subjected to neonatal hypoxia-ischemia. Pediatr Res 2014;76:46-53.

25. Sheldon RA, Sadjadi R, Lam M, Fitzgerald R, Ferriero DM. Alteration in downstream hypoxia gene signaling in neonatal glutathione peroxidase overexpressing mouse brain after hypoxia-ischemia. Dev Neurosci 2015;37:398-406.

26. Nanduri J, Wang N, Yuan G, Khan SA, Souvannakitti D, Peng YJ, et al. Intermittent hypoxia degrades HIF-2alpha via calpains resulting in oxidative stress: implications for recurrent apnea-induced morbidities. Proc Natl Acad Sci U S A 2009;106:1199-204.

27. Zhu C, Yu J, Pan Q, Yang J, Hao G, Wang Y, et al. Hypoxia-inducible factor-2 alpha promotes the proliferation of human placenta-derived mesenchymal stem cells through the MAPK/ERK signaling pathway. Sci Rep 2016;6:35489.

28. Koeppen M, Lee JW, Seo SW, Brodsky KS, Kreth S, Yang IV, et al. Hypoxia-inducible factor 2-alpha-dependent induction of amphiregulin dampens myocardial ischemia-reperfusion injury. Nat Commun 2018;9:816.

29. Semenza GL, Prabhakar NR. The role of hypoxia-inducible factors in carotid body (patho) physiology. J Physiol 2018;596:2977-83.

30. Chavez-Valdez R, Martin LJ, Flock DL, Northington FJ. Necrostatin-1 attenuates mitochondrial dysfunction in neurons and astrocytes following neonatal hypoxia-ischemia. Neuroscience 2012;219:192203.

31. Epstein CJ, Avraham KB, Lovett M, Smith S, Elroy-Stein O, Rotman G, et al. Transgenic mice with increased $\mathrm{Cu} / \mathrm{Zn}$-superoxide dismutase activity: animal model of dosage effects in Down syndrome. Proc Natl Acad Sci U S A 1987;84:8044-8. 